\title{
Achievement Growth in Children With Learning Difficulties in Mathematics: Findings of a Two-Year Longitudinal Study
}

\author{
Nancy C. Jordan, David Kaplan, and Laurie B. Hanich \\ University of Delaware
}

\begin{abstract}
The reading and mathematics growth of 180 children was examined over 4 points, spanning 2 nd and 3 rd grades. Initially, 4 achievement groups were identified: difficulties in mathematics but not in reading (MD only), difficulties in mathematics as well as in reading (MD-RD), difficulties in reading but not in mathematics (RD only), and normal achievement in mathematics and in reading. When IQ, income, ethnicity, and gender were held constant, the MD-only group grew at a faster rate in mathematics than did the MD-RD group. In reading, the RD-only and MD-RD groups grew at about the same rate. Reading abilities influence children's growth in mathematics, but mathematics abilities do not influence children's growth in reading.
\end{abstract}

Increasingly, state and local agencies are using high-stakes assessments to make important educational decisions. Although there are serious consequences for children who fail them, federal law, under the Individuals with Disabilities Education Act, requires that children with learning disabilities be included in the assessments. Typically high-stakes testing in mathematics begins at the end of third grade. However, little is known about the early achievement growth trajectories of children who are behind in this subject area. For example, are the growth rates for children who show mathematics difficulties (MD) in early primary school different from those for children who show no difficulties? Do some children with MD catch up in their achievement levels while others stay behind? We addressed these issues in the present study by examining children's early achievement in mathematics longitudinally. Children were individually assessed at four time points over a 2-year period, spanning second and third grades. At the start of the study, we identified two groups of children with MD, that is, children with difficulties in mathematics but not in reading (MD only) and children with difficulties in mathematics and difficulties in reading (MD-RD). For contrast, we also identified two groups of children without MD, namely children with difficulties in reading but not in mathematics (RD only) and children with normal achievement in mathematics and in reading (NA).

Although many studies define children with MD as a single group of low achievers (e.g., Geary, 1990; Geary, Brown, \& Samaranayake, 1991; Ostad, 1997; Russell \& Ginsburg, 1984), young children with MD only show a different pattern of cognitive deficits than do children with MD-RD. Recently, Hanich, Jordan, Kaplan, and Dick (2001) found that second graders with MD,

Nancy C. Jordan, David Kaplan, and Laurie B. Hanich, School of Education, University of Delaware.

This study was supported by National Institute of Child Health and Human Development Grant HD36672. We are very grateful to the children and teachers who participated in this project for their generous cooperation.

Correspondence concerning this article should be addressed to Nancy C. Jordan, School of Education, University of Delaware, Newark, Delaware 19716. E-mail: njordan@udel.edu regardless of whether they were MD only or MD-RD, performed worse than NA children in most areas of mathematical cognition. However, children with MD only outperformed children with MD-RD on orally presented arithmetic combinations (e.g., "How much is $8+7$ ") and on story problems (e.g., "Jen had 7 pennies. Then she gave some pennies to Joe. Now Jen has 2 pennies. How many pennies did she give to Joe?"). The two MD groups did not differ on tasks assessing approximate arithmetic or estimation (e.g., $50-9=11$ or 40), place value, rapid fact retrieval, calculation principles, and written computation with multidigits. Children with MD only seem to have an advantage over children with MD-RD on mathematical tasks that may be mediated by language but not on ones that depend more on understanding of numerical magnitudes, visuo-spatial processing, and automaticity. Geary, Hamson, and Hoard (2000), Geary, Hoard, and Hamson (1999), Jordan and Hanich (2000), and Jordan and Montani (1997) report similar findings with subgroups of primary school children with MD.

To date, few studies have examined mathematics difficulties from a longitudinal developmental perspective. Most approaches to studying children with MD assess outcomes at a single time point (Jordan, Hanich, \& Uberti, in press). However, measurement with only one time point cannot determine a child's growth rate, which is fundamental to understanding learning and learning difficulties (Francis, Shaywitz, Stuebing, Shaywitz, \& Fletcher, 1994). Measurement of growth through longitudinal investigations has been a primary interest in the study of reading difficulties (e.g., Blachman, 1994; Byrne, Freebody, \& Gates, 1992; Francis, Shaywitz, Stuebing, Shaywitz, \& Fletcher, 1996). For example, growth curve modeling has been used to examine whether children with reading difficulties are characterized by developmental lags or by cognitive deficits (S. E. Shaywitz, Shaywitz, Fletcher, \& Escobar, 1990) and to examine reading skill development in children who have received early interventions and later remediation (Foorman et al., 1997). Much less work, however, has been done in mathematics difficulties, although in a few studies these difficulties have not been stable over time. For example, Silver, Pennett, Black, Fair, and Balise (1999) found that a classification of isolated arithmetic weaknesses is less stable over a year and a half period 
than is a classification of pervasive weaknesses in arithmetic, reading, and spelling. Moreover, Geary (1990), Geary et al. (1991), and Geary et al. (2000) identified a group of "variable" children who showed mathematics difficulties on an achievement test in first grade but not in second grade. Unlike children with persistent MD, variable children do not show underlying deficits in numerical or arithmetical cognition. They appeared to have outgrown their early developmental delays or have been misidentified.

In the present study, we built on previous research in mathematics difficulties in several ways. First, we used educationally relevant classifications of children (i.e., MD only vs. MD-RD). Second, we measured children's growth rates in reading and mathematics within a longitudinal framework. We began our study in second grade because this is the earliest point at which mathematics difficulties can be reliably identified, at least with current testing instruments (Geary et al., 1991). In addition to looking at overall mathematics performance, our data allowed us to look at performance in mathematics calculation and applied problem solving separately. Likewise, in reading we examined overall reading performance as well as performance in word decoding and passage comprehension. Our longitudinal data were analyzed by means of growth curve modeling, a procedure that has been used extensively by researchers in numerous fields for the study of intraindividual differences in change (Bryk \& Raudenbush, 1992; Rogosa, Brandt, \& Zimowski, 1982; Willett, 1988; Willett \& Sayer, 1994). Third, we balanced our subgroups as closely as possible with respect to ethnicity, income level, and gender, allowing us to use these variables as controls in the growth models.

We also collected IQ data on all children (when they were in third grade) to determine the effects of underlying cognitive abilities on children's growth. Finally, we recorded whether children were receiving specialized interventions in reading and mathematics, whether children were retained at the end of second grade, and what type of mathematics program children were taught with to determine the impact of these factors on achievement growth. Regarding the latter variable, participants in the study (across achievement groups) were taught with one of two distinct approaches: a problem-centered mathematics approach, with little emphasis on facts or algorithms, or a more traditional approach, which provides more explicit instruction in mathematics skills.

We predicted that children with MD-RD would grow at a slower rate than children with MD only in mathematics achievement because of their lack of compensatory strengths in reading. We did not predict that children with MD-RD would grow more slowly than children with RD only in reading achievement, particularly in word decoding, because "garden-variety" poor readers develop in a fashion similar to children with specific reading problems (e.g., Shaywitz, Escobar, Shaywitz, Fletcher, \& Makuch, 1992). We also predicted that achievement growth rates would be affected by income level and intellectual ability. That is, holding achievement group constant, we expected low-income children and children with lower intellectual functioning to grow at a slower rate than middle-income children and children with higher intellectual functioning. Finally, we predicted that instruction in mathematics might have a differential effect on children's growth, according to their achievement group. That is, children with MD might benefit from more explicit instruction in skills more than children without MD.
Method

\section{Participants}

Participants were 180 second-grade children in northern Delaware: 46 children had difficulties in mathematics but not in reading (MD only), 42 children had difficulties in mathematics and in reading (MD-RD), 45 children had difficulties in reading but not in mathematics (RD only), and 47 children had normal achievement in reading and in mathematics (NA). Children were selected from a screening pool of over 600 children in the fall of second grade. The screening procedures and original sample have been described in detail elsewhere (Hanich et al., 2001). Participants in the present study completed all phases of the 2-year longitudinal project.

Over 2 years, the total attrition rate was $30(13 \%)$ out of a total of 210 children. Broken down by achievement group, the attrition rate was 7 (11\%) for the MD-only group, 10 (19\%) for the MD-RD group; $5(10 \%)$ for the RD-only group; and 8 (14\%) for the NA group. At the beginning of second grade (Year 1), all children came from six schools in the same public school district. In third grade (Year 2), the majority of children were still attending the original six schools. We were able to follow 13 children who moved to three other schools in the district or to schools in three neighboring districts. Thirty other children either moved too far away to be followed or could not be located.

Participant screening took place in the fall of second grade (mid-October to early November). Reading and mathematics achievement levels were assessed with the Woodcock-Johnson Psycho-Educational Battery-Revised, Form A (WJ; Woodcock \& Johnson, 1990). The WJ is an individually administered diagnostic test battery with norms from kindergarten through adulthood. It has been used extensively to identify learning problems, both clinically and for research (Francis et al., 1996). Children were given the WJ Broad Reading composite test (where the internal consistency reliability quotient is .98), which includes the Letter-Word Identification and Passage Comprehension subtests and the Broad Mathematics composite test (where the internal consistency reliability quotient is .94), which includes the Calculation and Applied Problems subtests.

Children with Broad Mathematics composite scores at or below the 35th percentile were classified as MD, and children with Broad Reading composite or Letter-Word Identification subtest scores at or below the 35th percentile were classified as RD. Percentile scores were based on grade level norms. Although the 35th percentile cutoff is somewhat higher than is typically used in research of learning disabilities, it was necessary to ensure an adequate sample size in each achievement subgroup (Geary et al., 2000; Hanich et al., 2001). Because mathematics achievement tests are based on many different types of items, the scores of children with MD might mask more specific deficits. In other words, children with MD often are average in some categories of items but have actual deficits in others (Hanich et al., 2001). Thus on a broad-based achievement test, such as the WJ, an achievement level at the 35th percentile may be associated with more specific deficits.

Children in the MD-only and the RD-only groups had at least a 10-point discrepancy between mathematics and reading achievement. The average mathematics and reading discrepancy was 49 percentile points for the MD-only group, 33 percentile points for the RD-only group, 4 percentile points for the MD-RD group, and 3 percentile points for the NA group. The mean reading and mathematics scores (for composites and the LetterWord Identification subtest) by achievement group are presented in Table 1 . These scores represent baseline data for our longitudinal study. The gender, ethnicity, and income level of children within each achievement group also are presented in Table 1. Children were considered to be low income if they qualified for the subsidized lunch program in second grade.

\section{Materials and Data Collection Procedure}

Reading and mathematics achievement. In addition to being given the WJ Broad Reading and Broad Mathematics composite tests in the fall of 
Table 1

Mean Achievement Scores and Descriptive Information About Participants, by Achievement Group

\begin{tabular}{|c|c|c|c|c|c|c|c|c|c|c|c|}
\hline \multirow{3}{*}{$\begin{array}{l}\text { Achievement } \\
\text { group }\end{array}$} & \multirow[b]{3}{*}{$N$} & \multirow[b]{3}{*}{ Boys } & \multirow[b]{3}{*}{ Girls } & \multirow[b]{3}{*}{ Minority (\%) } & \multirow[b]{3}{*}{ Low SES (\%) } & \multicolumn{6}{|c|}{ Percentile score } \\
\hline & & & & & & \multicolumn{2}{|c|}{$\begin{array}{l}\text { Reading } \\
\text { composite }^{\mathrm{a}}\end{array}$} & \multicolumn{2}{|c|}{$\begin{array}{l}\text { Letter-Word } \\
\text { Identification }^{\mathrm{a}}\end{array}$} & \multicolumn{2}{|c|}{$\begin{array}{l}\text { Mathematics } \\
\text { composite }^{\mathrm{a}}\end{array}$} \\
\hline & & & & & & $M$ & $S D$ & $M$ & $S D$ & $M$ & $S D$ \\
\hline MD only & 46 & 21 & 25 & 61 & 46 & 71.67 & 14.32 & 66.34 & 18.02 & 22.87 & 9.74 \\
\hline MD-RD & 42 & 23 & 19 & 48 & 50 & 24.91 & 13.43 & 21.01 & 11.41 & 21.07 & 10.80 \\
\hline RD only & 45 & 29 & 16 & 60 & 56 & 26.96 & 10.42 & 23.24 & 9.65 & 60.42 & 16.03 \\
\hline NA & 47 & 23 & 24 & 43 & 40 & 71.96 & 13.27 & 63.66 & 16.46 & 68.81 & 12.02 \\
\hline
\end{tabular}

Note. Within each achievement group, children identified as ethnic minority were primarily African American ( $>80 \%$ for each achievement group). $\mathrm{MD}=$ children with difficulties in mathematics but not in reading; $\mathrm{MD}-\mathrm{RD}=$ children with difficulties in mathematics as well as in reading; RD = children with difficulties in reading but not in mathematics; NA = children with normal achievement in mathematics and in reading; SES = socioeconomic status.

${ }^{a}$ Woodcock-Johnson Psycho-Educational Battery-Revised, Form A.

second grade, as noted above, children took the WJ on three other occasions: late April to early May of second grade (Form B); mid-October to early November of third grade (Form A); and late April to early May of third grade (Form B). Children were tested individually in their schools by a trained experimenter. Each testing occasion spanned a 2- to 3-week time period.

For the longitudinal analyses, the Rasch-scaled scores from the WJ were used. The Rasch-scaled scores (referred to as W scores on the WJ) are the transformation of the number correct for each subtest to provide a score with equal interval properties and a constant metric. A score of 500 corresponds to the average performance at the beginning of fifth grade. Because of their equal interval properties and constant metric, Raschscaled scores are well suited for longitudinal studies of individual growth (Bryk \& Raudenbush, 1987; Francis et al., 1996).

Intellectual abilities. In January and February of third grade, children were given the Wechsler Abbreviated Scale of Intelligence (WASI; Wechsler, 1999). The mean WASI IQ score is 100 with a standard deviation of 15 points. The internal consistency reliability quotients of the WASI are .95 for 8 -year-olds and .96 for 9 -year-olds.

Other data. Throughout the study, we collected data regarding the specialized intervention programs children were receiving in reading and in mathematics (e.g., special education as well as other remedial assistance outside of the normal curricula) and the type of mathematics instructional program that was used in the classroom in second and third grade. The problem-centered programs used by the district were Investigations in Number, Data, and Space (1998) or Math Trailblazers (1997), and the traditional program was Math (1998). We also kept track of children who were retained at the end of second grade.

\section{Data Analysis Procedure}

Our main data analytic procedure was growth curve modeling. Growth curve models can be viewed as falling within the class of multilevel linear models (Bryk \& Raudenbush, 1992), where Level 1 represents intraindividual differences in initial status and growth rate and Level 2 represents interindividual differences in initial status and growth rate. In this article we will first consider a simple growth model for the WJ W scores simply as a function of time. We write the Level 1 equation expressing the WJ scores over time within an individual as follows:

$$
\mathrm{WJ}_{i p}=\pi_{0 p}+\pi_{1 p} t_{i}+\varepsilon_{i p},
$$

where $\mathrm{WJ}_{i p}$ is the math or reading $\mathrm{WJ}$ score for student $p$ at time $i, \pi_{0 p}$ represents the initial status at time $t=0$ (for our study this will be fall semester of the grade), $\pi_{1 p}$ represents the growth trajectory, and $t_{i}$ repre- sents a temporal dimension that is assumed to be the same for all individuals. In the case of our study, the temporal dimension is semester, with students measured in the fall and spring of the second grade and fall and spring of the third grade. Finally, $\varepsilon_{i p}$ is the disturbance term in the Level 1 equation representing the influence of omitted variables for student $p$ at time $i$. A more specific assumption regarding the errors is that they are normally and independently distributed with a mean of zero and a common variance (Bryk \& Raudenbush, 1992).

A major benefit of growth curve modeling is that it can be extended to handle predictors of individual differences in the initial status and growth rate parameters. In this case, two models are specified, one for the initial status parameter and one for the growth rate parameter. Predictors of initial status and growth rate are referred to as time-invariant predictors. In our study, achievement group membership, gender (male $=1$ ), ethnicity (minority $=1$ ), income level (low income $=1$ ), and IQ will be used as time-invariant predictors. It should be noted that IQ was centered on the sample mean.

In our study, the time-invariant predictors of major interest are group membership and the remaining predictors. Because achievement group membership is dummy coded with MD-RD serving as the reference group, three dummy coded vectors are specified. Thus, the Level 2 model for the initial status (IS) and growth rate (GR) can be written as follows:

$$
\begin{aligned}
\mathrm{IS}_{p}= & \mu_{\mathrm{IS}}+\gamma_{1, \mathrm{IS}}(\mathrm{NA})_{p}+\gamma_{2, \mathrm{IS}}(\mathrm{RD} \text { only })_{p}+\gamma_{3, \mathrm{IS}}(\mathrm{MD} \text { only })_{p} \\
+\gamma_{4, \mathrm{IS}}(\text { male })_{p}+\gamma_{5, \mathrm{IS}}(\text { minority })_{p}+\gamma_{6, \mathrm{IS}}(\text { income })_{p} & \\
& +\gamma_{7, \mathrm{IS}}(\mathrm{IQ})_{p}+\zeta_{0 p}
\end{aligned}
$$

and

$$
\begin{aligned}
\mathrm{GR}_{p}=\mu_{\mathrm{GR}}+\gamma_{1, \mathrm{GR}}(\mathrm{NA})_{p} & +\gamma_{2, \mathrm{GR}}(\mathrm{RD} \text { only })_{p}+\gamma_{3, \mathrm{GR}}(\mathrm{MD} \text { only })_{p} \\
+\gamma_{4, \mathrm{GR}}(\text { male })_{p}+\gamma_{5, \mathrm{GR}}(\text { minority })_{p} & \\
& +\gamma_{6, \mathrm{GR}}(\text { income })_{p}+\gamma_{7, \mathrm{GR}}(\mathrm{IQ})_{p}+\zeta_{1 p}
\end{aligned}
$$

where $\mu_{\mathrm{IS}}$ and $\mu_{\mathrm{GR}}$ are intercept parameters representing mean population initial status and mean population growth rate for White female MD-RD students with IQ scores at the mean of the sample; the parameters $\gamma_{1}, \gamma_{2}$, and $\gamma_{3}$ give the mean differences in initial status and growth rate between the specific achievement groups and the MD-RD group holding constant gender, ethnicity, income, and IQ; the coefficient $\gamma_{4}$ gives the mean difference between boys and girls on initial status and growth rate holding constant achievement group membership, ethnicity, income, and IQ; the coefficient $\gamma_{5}$ gives the mean difference between minority and nonminority 
students on initial status and growth rate holding constant achievement group membership, gender, income, and IQ; the coefficient $\gamma_{6}$ gives the mean difference between low-income and middle-income students on initial status and growth rate holding constant achievement group membership, gender, ethnicity, and IQ; and the coefficient $\gamma_{7}$ gives the effect of IQ on initial status and growth rate holding constant achievement group membership, gender, ethnicity, and income. The $\zeta$ s are disturbance terms containing the effects of omitted variables in their respective equations. The derivations of these parameters are discussed in detail elsewhere (e.g., Bryk \& Raudenbush, 1992).

Research by Muthén (1991) and Willett and Sayer (1994) has shown how the general growth model described in the previous section can also be incorporated into a structural equation-modeling framework. For the purposes of this study, growth curve modeling will be specified as a structural equation model utilizing the software program AMOS (Arbuckle, 1999).

\section{Results}

\section{Growth Curve Analyses}

Growth curve analyses were performed on the WJ Broad Mathematics and Broad Reading composites as well as on the subtests for each composite scale (Calculation, Applied Problems, LetterWord Identification, and Passage Comprehension). Analyses modeled the effects of achievement group membership and timeinvariant predictors (i.e., gender, ethnicity, income, and IQ) on growth in mathematics and reading achievement. The format of the growth curve modeling output follows that as shown in Table 2. For each analysis, a baseline model was specified, which provides an estimate of the intercept (achievement W scores as measured in the fall of second grade) and slope (rate of growth over the four time points of the study). Model 1 adds the effects of achievement group membership to the baseline model. Model 2 adds the effects of predictor variables to Model 1 .

\section{Mathematics Achievement}

Broad Mathematics composite. Table 2 presents the results of the growth curve model for achievement on the Broad Mathematics composite of the WJ. The intercept and slope in mathematics achievement for the total sample are depicted in the baseline model (see Table 2). The average second-grade W score in Broad Mathematics was 460.89 and increased an average of 7.63 points over 2 years.

The results of adding achievement group membership to the growth curve model are summarized in Model 1 (Table 2). For Broad Mathematics and all subsequent models, the MD-RD group is used as the reference group for achievement group comparisons, and thus the average intercept and slope pertain to the MD-RD group. The average second-grade $\mathrm{W}$ score in Broad Mathematics for the MD-RD group was lower than that for the total sample (451.66), and the slope was slightly higher (7.81). When examining achievement group differences, we found that the NA and RD-only groups had significantly higher second-grade W scores in Broad Mathematics than the MD-RD group, whereas children with MD only started at about the same achievement level as children with MD-RD (see Model 1). Regarding growth rates, the MD-only group grew significantly faster than the MD-RD group, and the RD-only group grew significantly slower than the MD-RD group. The average growth trajectories for the four achievement groups on the WJ Broad Mathematics composite are depicted in
Table 2

Woodcock-Johnson Broad Mathematics Composite Growth Curve Results

\begin{tabular}{|c|c|c|c|}
\hline \multirow[b]{2}{*}{ Effect } & \multicolumn{3}{|c|}{ Maximum likelihood estimate } \\
\hline & Baseline model $^{\mathrm{a}}$ & Model $1^{\mathrm{b}}$ & Model $2^{\mathrm{c}}$ \\
\hline Intercept & $460.89 *$ & $451.66^{*}$ & $451.57 *$ \\
\hline Slope & $7.63 *$ & $7.81 *$ & $8.55 *$ \\
\hline Variance (intercept) ${ }^{\mathrm{d}}$ & $75.20 *$ & $22.15 *$ & $17.51 *$ \\
\hline Variance (slope) & $2.60 *$ & $2.35^{*}$ & 1.86 \\
\hline$r$ (intercept slope) & -0.16 & 0.24 & 0.08 \\
\hline Intercept on NA & & $17.96^{*}$ & $15.73 *$ \\
\hline Slope on NA & & -0.51 & $-1.46^{*}$ \\
\hline Intercept on RD only & & $15.29 *$ & $14.43 *$ \\
\hline Slope on RD only & & $-2.03 *$ & $-2.29 *$ \\
\hline Intercept on MD only & & 2.11 & 1.16 \\
\hline Slope on MD only & & $2.17 *$ & $1.87 *$ \\
\hline Intercept on gender & & & -0.56 \\
\hline Slope on gender & & & 0.26 \\
\hline Intercept on ethnicity & & & 1.15 \\
\hline Slope on ethnicity & & & -0.08 \\
\hline Intercept on income & & & 1.81 \\
\hline Slope on income & & & $-0.86^{*}$ \\
\hline Intercept on IQ & & & $0.20 *$ \\
\hline Slope on IQ & & & $0.07 *$ \\
\hline
\end{tabular}

Note. $\mathrm{NA}=$ children with normal achievement in mathematics and in reading; $\mathrm{RD}$ only = children with difficulties in reading but not in mathematics; MD only = children with difficulties in mathematics but not in reading; MD-RD only = children with difficulties in mathematics as well as in reading.

${ }^{a}$ Baseline model: no achievement groups and no predictor variables. ${ }^{\mathrm{b}}$ Model 1: achievement groups (MD-RD as reference group) and no predictor variables. ${ }^{\mathrm{c}}$ Model 2: achievement groups and time-invariant predictor variables (gender, ethnicity, Income Year 1, full scale IQ). ${ }^{\mathrm{d}}$ The variance of the corresponding parameter. $* p<.05$.

Figure 1, with those results consistent with the results of the growth model analyses.

The results with time-invariant predictors of gender, ethnicity, income, and IQ added to the model are in Model 2 (see Table 2). Here, the intercept and slope pertain to White girls with average IQs in the MD-RD group from middle-income families. The average second-grade Broad Mathematics W score for this group was 451.57 and the slope was 8.55. There was a significant effect of IQ on the intercept and a significant effect of IQ and income on the slope. Gender and ethnicity were not significant predictors of the slope or intercept. Children with higher IQs had higher W scores at the beginning of second grade and grew significantly faster in mathematics achievement than children with lower IQs, when the other predictors in the model were held constant. Lowincome children had a significantly slower growth rate than middle-income children. When the other predictors were held constant, children with MD only grew significantly faster than children with MD-RD (see Model 2). Children in the NA and the RD-only groups grew significantly slower than children in the MD-RD group.

An interesting result was the change from Model 1 to Model 2 with respect to the difference between the MD-RD and NA groups. Specifically, we found that the MD-RD versus NA comparison in Model $1(-0.51)$ was nonsignificant, whereas the 


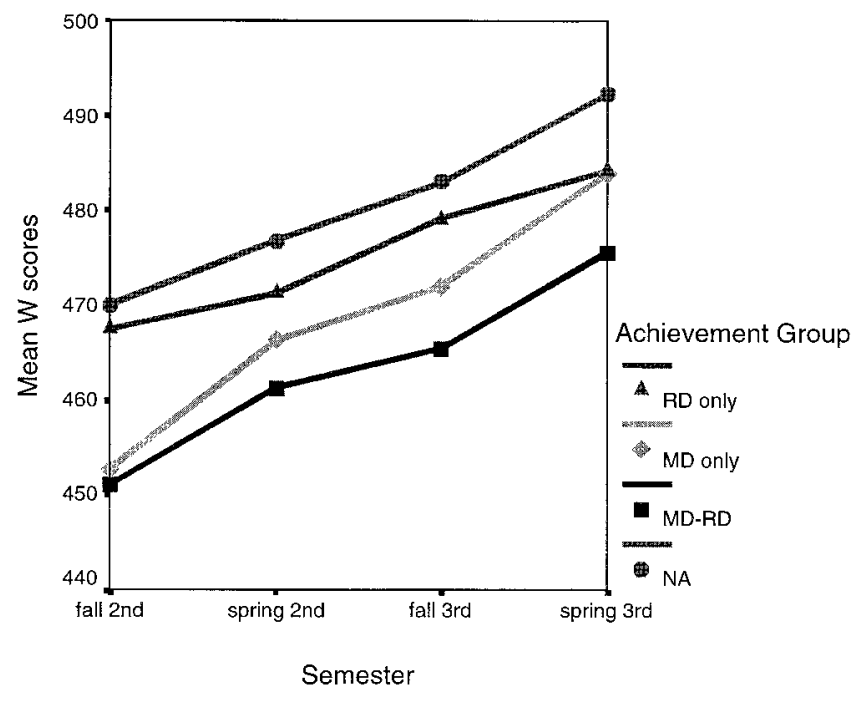

Figure 1. Growth trajectories on the Woodcock-Johnson PsychoEducational Battery-Revised, Form A (WJ), Broad Mathematics composite, by achievement group. Points represent the mean Broad Mathematics scores. W scores = Rasch-scaled scores from the $\mathrm{WJ}$; RD only = difficulties in reading but not in mathematics; MD only $=$ difficulties in mathematics but not in reading; MD-RD = difficulties in mathematics as well as in reading; $\mathrm{NA}=$ normal achievement in mathematics and in reading.

MD-RD versus NA comparison in Model 2 (-1.46) was significant. To further examine differences between the difficulty groups and the NA group, we conducted several supplementary analyses in which the NA group was assigned as the reference group for comparisons. This was done to isolate the effect of the combined difficulties from that of math difficulties only. We reasoned that if the NA versus MD-only comparison did not change much with the addition of the time-invariant predictors (Model 1 vs. Model 2) when compared with the NA versus MD-RD contrast, this would be taken as evidence of the comorbidity of MD and RD. There was a slight change in the regression weight for the difference between the NA and MD-only group from Model 1 (2.67) to Model 2 (3.33). However, there was a substantial increase in the regression weight for the difference between the NA and MD-RD comparison from Model 1 (0.51) to Model 2 (1.46). The significant difference in growth rates between the NA and MD-RD groups after adding gender, ethnicity, income, and IQ might be explained as a "masking" effect of the omitted time-invariant predictors in Model 1. That is, when these variables were not in the model (Model 1), the reading disability of the MD-RD group was masked. However, when these variables were added to the model, such that the groups were held constant on these variables, the "pure" effect of the reading disability emerged.

Calculation subtest. Results of a growth curve model for achievement on the WJ Calculation subtest are contained in Table 3. The average second-grade $\mathrm{W}$ score in Calculation was 452.62 and increased an average of 7.66 points over 2 years (see baseline model, Table 2). Figure 2 displays the average growth trajectories, by achievement group, on the WJ Calculation subtest.

When achievement group membership was added to the model, the average $\mathrm{W}$ score in Calculation for the MD-RD group was
445.76 and the slope was 7.70 (Model 1, Table 3). The effect of achievement group membership for Calculation was comparable with that for Broad Mathematics. The NA and the RD-only groups had significantly higher $\mathrm{W}$ scores than the MD-RD group, whereas the MD-only group started at approximately the same point. The MD-only group grew significantly faster than the MD-RD group, and the MD-RD group grew significantly faster than the RD-only group.

When the predictor variables were entered into the model, the values of the slope and intercept did not change much (Model 2, Table 3). The average W score for White girls with average IQs in the MD-RD group from middle-income families was 445.63 and the slope was 8.32. There was a significant effect of gender and income on the intercept for Calculation, favoring girls and lowincome children when the other predictors were held constant. There was a significant effect of IQ on the slope for Calculation. Children with higher IQs grew at a faster pace than children with lower IQs. When the predictor variables were held constant, the effects of achievement group revealed that the NA and RD-only groups started significantly higher in Calculation than the MD-RD group. The MD-only group grew significantly faster than the MD-RD group, which in turn grew significantly faster than both the NA and the RD-only groups.

As with the Broad Mathematics composite, we found a similar change in the results of the MD-RD versus NA comparison when

Table 3

Woodcock-Johnson Mathematics Calculation Subtest Growth Curve Results

\begin{tabular}{|c|c|c|c|}
\hline \multirow[b]{2}{*}{ Effect } & \multicolumn{3}{|c|}{ Maximum likelihood estimate } \\
\hline & Baseline model $^{\mathrm{a}}$ & Model $1^{\mathrm{b}}$ & Model $2^{\circ}$ \\
\hline Intercept & $452.62 *$ & $445.76^{*}$ & $445.63 *$ \\
\hline Slope & $7.66^{*}$ & $7.70^{*}$ & $8.32 *$ \\
\hline Variance (intercept) ${ }^{\mathrm{d}}$ & $57.94 *$ & $21.50 *$ & $18.55 *$ \\
\hline Variance (slope) & 3.10 & 2.38 & 1.51 \\
\hline$r$ (intercept slope) & -0.34 & -0.03 & -0.07 \\
\hline Intercept on NA & & $14.29 *$ & $13.54 *$ \\
\hline Slope on NA & & -0.65 & $-1.83^{*}$ \\
\hline Intercept on RD only & & $12.41 *$ & $12.10^{*}$ \\
\hline Slope on RD only & & $-2.08^{*}$ & $-2.46^{*}$ \\
\hline Intercept on MD only & & 0.68 & 0.07 \\
\hline Slope on MD only & & $2.52 *$ & $2.14 *$ \\
\hline Intercept on gender & & & $-2.43 *$ \\
\hline Slope on gender & & & 0.60 \\
\hline Intercept on ethnicity & & & 1.33 \\
\hline Slope on ethnicity & & & 0.23 \\
\hline Intercept on income & & & $2.49 *$ \\
\hline Slope on income & & & -1.10 \\
\hline Intercept on IQ & & & 0.08 \\
\hline Slope on IQ & & & $0.09 *$ \\
\hline
\end{tabular}

Note. $\mathrm{NA}=$ children with normal achievement in mathematics and in reading; $\mathrm{RD}$ only $=$ children with difficulties in reading but not in mathematics; MD only = children with difficulties in mathematics but not in reading; MD-RD only $=$ children with difficulties in mathematics as well as in reading.

${ }^{a}$ Baseline model: no achievement groups and no predictor variables. ${ }^{\mathrm{b}}$ Model 1: achievement groups (MD-RD as reference group) and no predictor variables. ${ }^{\mathrm{C}}$ Model 2: achievement groups and time-invariant predictor variables (gender, ethnicity, Income Year 1, full scale IQ). ${ }^{\mathrm{d}}$ The variance of the corresponding parameter.

$* p<.05$. 


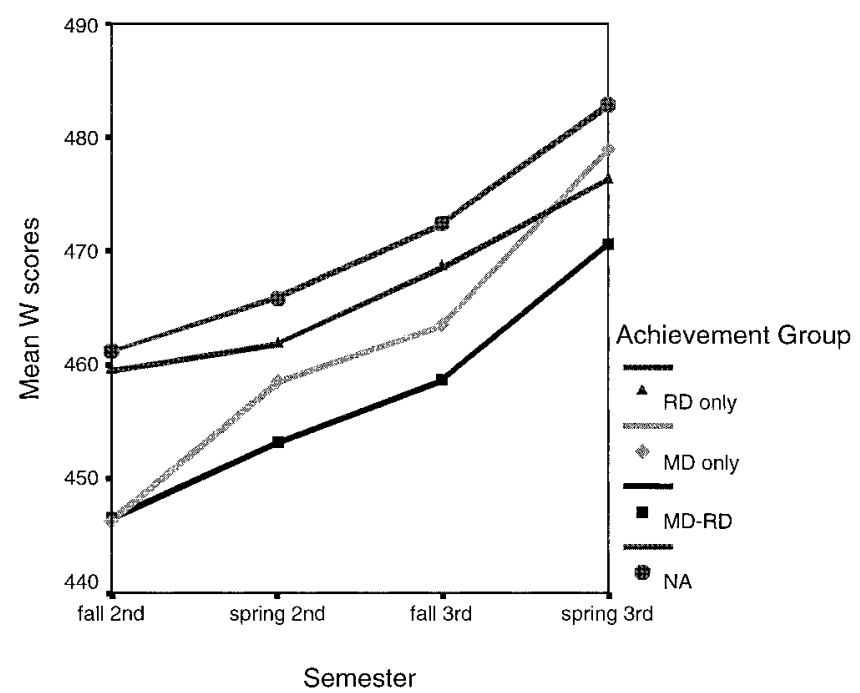

Figure 2. Growth trajectories on the Woodcock-Johnson PsychoEducational Battery-Revised, Form A (WJ), Calculation subtest, by achievement group. Points represent the mean Calculation scores. W scores $=$ Rasch-scaled scores from the WJ; RD only = difficulties in reading but not in mathematics; $\mathrm{MD}$ only = difficulties in mathematics but not in reading; $\mathrm{MD}-\mathrm{RD}=$ difficulties in mathematics as well as in reading; $\mathrm{NA}=$ normal achievement in mathematics and in reading.

adding the time-invariant predictors. Again, we speculate that this change was due to the masking effect previously discussed with respect to the Broad Mathematics composite.

Applied Problems subtest. The results of a growth curve model for achievement on the WJ Applied Problems subtest are in Table 4. The average growth trajectories, by achievement group, on Applied Problems are depicted in Figure 3. The average second-grade $\mathrm{W}$ score for the intercept was higher for the Applied Problems subtest than for the Calculation subtest (470.17 and 452.62, respectively; baseline model, Table 4).

The effects of adding achievement group membership are summarized in Model 1 (Table 4). The average second-grade W score for the MD-RD group was 459.16 and the slope was 7.32. The pattern of achievement group effects in Model 1 for Applied Problems was the same as that of the achievement group effects in Model 1 for Calculation. That is, the NA and RD-only groups had significantly higher $\mathrm{W}$ scores than the MD-RD group, whereas the MD-only group started at approximately the same achievement level as the MD-RD group. The MD-only group grew significantly faster than the MD-RD group, which in turn grew significantly faster than the RD-only group.

When predictor variables were entered into the model, there was little change in the value of the intercept and slope. The initial W score for MD-RD girls with average IQs from middle-income families was 458.86 and the slope was 8.22 (Model 2, Table 4). The effect of IQ on the intercept was the only significant predictor variable in the model. Unlike in Model 2 for Calculation, gender and income level were not significant predictors of the intercept for Applied Problems. When accounting for the effects of the predictor variables, the same pattern of achievement group effects for Model 1 held for Model 2.
We did not find a similar pattern on Applied Problems as that on Broad Mathematics and Calculation with regard to the difference between the MD-RD and NA groups. For both Models 1 and 2, there was not a significant difference between the growth rates of the MD-RD and the NA groups on the Applied Problems subtest.

Summary. In all three areas (i.e., Broad Mathematics, Calculation, and Applied Problems), the NA and RD-only groups started with significantly higher second-grade $\mathrm{W}$ scores than the MD-RD group, whereas the MD-only group started at about the same achievement level. When the time-invariant predictors of income, gender, ethnicity, and IQ were held constant, children in the MD-RD group grew significantly faster than children in the NA and RD-only groups with respect to Broad Mathematics and Calculation, although they did not catch up to these groups. The MD-only group grew significantly faster than the MD-RD group regardless of the addition of the time-invariant predictors. On Applied Problems, the MD-RD group grew significantly faster than the RD-only group but not the NA group, and the MD-only group grew significantly faster than the MD-RD group. IQ was a significant predictor of initial achievement levels for Broad Mathematics and Applied Problems. In Calculation, gender and income were significant predictors of initial achievement levels. IQ was a significant predictor of growth in all areas of mathematics. Income was a predictor of growth only for Broad Mathematics.

Table 4

Woodcock-Johnson Mathematics Applied Problems Subtest Growth Curve Results

\begin{tabular}{|c|c|c|c|}
\hline \multirow[b]{2}{*}{ Effect } & \multicolumn{3}{|c|}{ Maximum likelihood estimate } \\
\hline & Baseline model $^{\mathrm{a}}$ & Model $1^{\mathrm{b}}$ & Model $2^{\mathrm{c}}$ \\
\hline Intercept & $470.17 *$ & $459.16^{*}$ & $458.86^{*}$ \\
\hline Slope & $7.16^{*}$ & $7.32 *$ & $8.22 *$ \\
\hline Variance (intercept) ${ }^{\mathrm{d}}$ & $97.13 *$ & $29.87 *$ & $18.51 *$ \\
\hline Variance (slope) & 1.34 & 1.52 & 1.23 \\
\hline$r$ (intercept slope) & 0.13 & 0.61 & 0.59 \\
\hline Intercept on NA & & $20.67 *$ & $17.09 *$ \\
\hline Slope on NA & & -0.07 & -0.76 \\
\hline Intercept on RD only & & $17.04 *$ & $15.60 *$ \\
\hline Slope on RD only & & $-1.71 *$ & $-1.80 *$ \\
\hline Intercept on MD only & & 3.47 & 2.23 \\
\hline Slope on MD only & & $1.73^{*}$ & $1.55^{*}$ \\
\hline Intercept on gender & & & 1.45 \\
\hline Slope on gender & & & -0.11 \\
\hline Intercept on ethnicity & & & 1.18 \\
\hline Slope on ethnicity & & & -0.51 \\
\hline Intercept on income & & & 1.23 \\
\hline Slope on income & & & -0.65 \\
\hline Intercept on IQ & & & $0.32 *$ \\
\hline Slope on IQ & & & 0.05 \\
\hline
\end{tabular}

Note. $\mathrm{NA}=$ children with normal achievement in mathematics and in reading; $\mathrm{RD}$ only = children with difficulties in reading but not in mathematics; MD only = children with difficulties in mathematics but not in reading; MD-RD only = children with difficulties in mathematics as well as in reading.

a Baseline model: no achievement groups and no predictor variables. ${ }^{\mathrm{b}}$ Model 1: achievement groups (MD-RD as reference group) and no predictor variables. ${ }^{\mathrm{c}}$ Model 2: achievement groups and time-invariant predictor variables (gender, ethnicity, Income Year 1, full scale IQ). ${ }^{\mathrm{d}}$ The variance of the corresponding parameter.

$* p<.05$. 


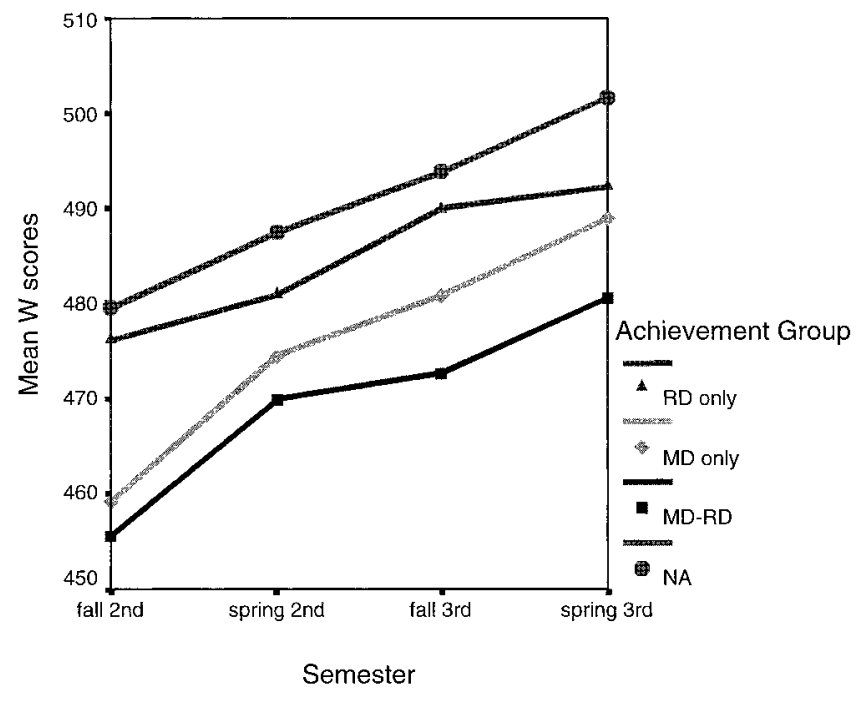

Figure 3. Growth trajectories on the Woodcock-Johnson PsychoEducational Battery—Revised, Form A (WJ), Applied Problems subtest, by achievement group. Points represent the mean Applied Problems scores. $\mathrm{W}$ scores $=$ Rasch-scaled scores from the WJ; RD only $=$ difficulties in reading but not in mathematics; $\mathrm{MD}$ only $=$ difficulties in mathematics but not in reading; MD-RD = difficulties in mathematics as well as in reading; $\mathrm{NA}=$ normal achievement in mathematics and in reading.

\section{Reading Achievement}

Broad Reading composite. The results of a growth curve model for achievement on the Broad Reading composite of the WJ are summarized in Table 5. The average second-grade $\mathrm{W}$ score in reading achievement was 460.85 and increased an average of 8.24 points over 2 years (baseline model). The correlation of the initial starting point and rate of change was statistically significant $(r=$ -0.73 ), meaning that higher second-grade $\mathrm{W}$ scores in Broad Reading were associated with slower rates of growth.

The results when achievement group membership was added to the model are in Model 1 (Table 5). The average second-grade W score for the MD-RD group in reading achievement was 445.22 and the slope was 10.20. The correlation between the intercept and slope was -0.37 and statistically significant. Regarding achievement group differences, the NA and MD-only groups had significantly higher $\mathrm{W}$ scores in Broad Reading than the MD-RD group. The RD-only group started at approximately the same achievement level as the MD-RD group. The MD-RD group grew significantly faster than the NA and the MD-only groups. The difference in the rate of growth between the RD-only and the MD-RD groups was not statistically significant for Broad Reading. The average growth trajectories for the four achievement groups on the WJ Broad Reading composite are in Figure 4.

The results of the model when gender, ethnicity, income, and IQ were added are in Model 2 (Table 5). The values of the intercept and the slope and the correlation between the intercept and slope were comparable with the values in the previous model. MD-RD White girls with average IQs from middle-income families had an average second-grade $\mathrm{W}$ score of 447.85 and a slope of 9.98 (Model 2). The correlation between the intercept and slope was statistically significant at -0.46 . The only statistically significant predictor variable in the model was the effect of IQ on the intercept. When the predictor variables in the model were held constant, the NA and MD-only groups had higher W scores in reading achievement than the MD-RD group. Children in the MD-RD group grew significantly faster than children in the NA and MD-only groups. The RD-only and MD-RD groups did not differ significantly in their rate of growth.

Letter-Word Identification subtest. Results of a growth curve model for achievement on the WJ Letter-Word Identification subtest are in Table 6. The average second-grade $\mathrm{W}$ score was 455.20 and the slope was 8.71 (baseline, Table 5). The average growth trajectories, by achievement group, for Letter-Word Identification are in Figure 5.

The results of the model after adding achievement group membership are in Model 1 (Table 6). The average second-grade W score for the MD-RD group was 440.38 and the slope was 9.92 . When examining achievement-group differences, we obtained the same pattern of results for Letter-Word Identification as for Broad Reading Model 1 (i.e., the NA and MD-only groups had significantly higher $\mathrm{W}$ scores in Letter-Word Identification than the MD-RD group, whereas the RD-only group started at about the same skill level). The MD-RD group grew significantly faster than the NA and MD-only groups but not the RD-only group.

When the predictor variables were entered into the model (Model 2, Table 6), the average second-grade W score in Letter-

Table 5

Woodcock-Johnson Broad Reading Composite Growth Curve Results

\begin{tabular}{|c|c|c|c|}
\hline \multirow[b]{2}{*}{ Effect } & \multicolumn{3}{|c|}{ Maximum likelihood estimate } \\
\hline & 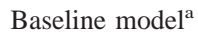 & Model $1^{\mathrm{b}}$ & Model $2^{\mathrm{c}}$ \\
\hline Intercept & $460.85^{*}$ & $445.22 *$ & $447.85 *$ \\
\hline Slope & $8.24 *$ & $10.20 *$ & $9.98 *$ \\
\hline Variance (intercept) ${ }^{\mathrm{d}}$ & $241.71 *$ & $78.09 *$ & $64.44 *$ \\
\hline Variance (slope) & $4.68 *$ & $2.85 *$ & $2.73 *$ \\
\hline$r$ (intercept slope) & $-0.73^{*}$ & $-0.37 *$ & $-0.46^{*}$ \\
\hline Intercept on NA & & $27.98 *$ & $23.51 *$ \\
\hline Slope on NA & & $-2.89 *$ & $-3.10 *$ \\
\hline Intercept on RD only & & 3.62 & 2.33 \\
\hline Slope on RD only & & -0.29 & -0.41 \\
\hline Intercept on MD only & & $27.33 *$ & $25.42 *$ \\
\hline Slope on MD only & & $-3.86^{*}$ & $-3.86 *$ \\
\hline Intercept on gender & & & -1.43 \\
\hline Slope on gender & & & 0.54 \\
\hline Intercept on ethnicity & & & 2.17 \\
\hline Slope on ethnicity & & & -0.20 \\
\hline Intercept on income & & & -1.97 \\
\hline Slope on income & & & 0.27 \\
\hline Intercept on IQ & & & $0.36^{*}$ \\
\hline Slope on IQ & & & 0.02 \\
\hline
\end{tabular}

Note. $\mathrm{NA}=$ children with normal achievement in mathematics and in reading; $\mathrm{RD}$ only $=$ children with difficulties in reading but not in mathematics; MD only = children with difficulties in mathematics but not in reading; MD-RD only = children with difficulties in mathematics as well as in reading.

${ }^{a}$ Baseline model: no achievement groups and no predictor variables. ${ }^{\mathrm{b}}$ Model 1: achievement groups (MD-RD as reference group) and no predictor variables. ${ }^{\mathrm{C}}$ Model 2: achievement groups and time-invariant predictor variables (gender, ethnicity, Income Year 1, full scale IQ). ${ }^{\mathrm{d}}$ The variance of the corresponding parameter. $* p<.05$. 


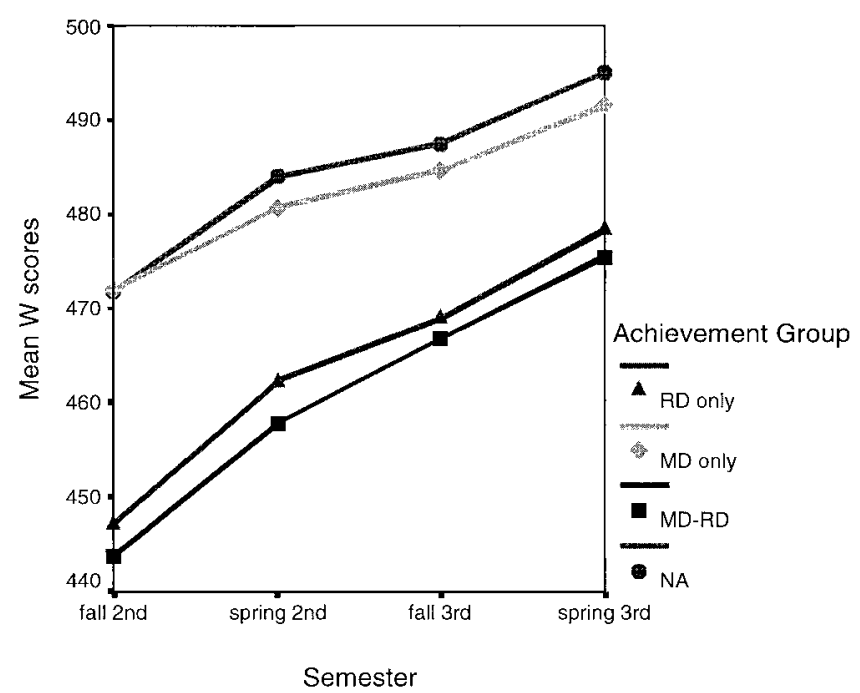

Figure 4. Growth trajectories on the Woodcock-Johnson PsychoEducational Battery-Revised, Form A (WJ), Broad Reading composite, by achievement group. Points represent the mean Broad Reading scores. W scores $=$ Rasch-scaled scores from the WJ; RD only $=$ difficulties in reading but not in mathematics; $\mathrm{MD}$ only = difficulties in mathematics but not in reading; $\mathrm{MD}-\mathrm{RD}=$ difficulties in mathematics as well as in reading; $\mathrm{NA}=$ normal achievement in mathematics and in reading.

Word Identification for MD-RD White girls with average IQs from middle-income families was 441.92 and the slope was 9.70. IQ was the only significant predictor for the slope and intercept. When the predictor variables were held constant, the effects of achievement group revealed the same pattern of achievement group differences as in Model 1. That is, children in the NA and MD-only groups had higher W scores and grew slower in LetterWord Identification than children in the MD-RD group; children in the RD-only group did not differ from children in the MD-RD group in the slope or the intercept.

Passage Comprehension subtest. The results of a growth curve model for achievement on the Passage Comprehension subtest are in Table 7. The average second-grade W score was higher for Passage Comprehension than for Letter-Word Identification (466.46 and 455.20, respectively; baseline model, Table 7). Values of the slope were slightly lower for Passage Comprehension than for Letter-Word Identification (7.97 vs. 8.71). The correlation between the intercept and slope was -0.83 and was statistically significant, suggesting that higher W scores were associated with lower rates of growth. The average growth trajectories, by achievement group, on Passage Comprehension are in Figure 6.

The average second-grade $\mathrm{W}$ score for the MD-RD group in Passage Comprehension was 450.73 and the slope was 10.62 (Model 1, Table 7). The correlation between the slope and intercept remained significant $(r=-0.60)$. The pattern of achievement group differences was identical to those for Broad Reading and Letter-Word Identification. The NA and MD-only groups had significantly higher W scores in Passage Comprehension than the MD-RD group, whereas the RD-only group was at about the same skill level. The NA and MD-only groups grew significantly slower than the MD-RD group, but there was not a significant difference in the rate of growth between the RD-only and the MD-RD groups.

Results of the model that included predictors of Passage Comprehension are in Model 2 (Table 7). The initial average W score for MD-RD White girls with average IQs from middle-income families was 454.57 and the slope was 4.78. The correlation between the intercept and slope was -0.65 and was statistically significant. The effect of IQ on the intercept was the only significant predictor in the model. When the predictors were held constant, the NA and MD-only groups had significantly higher W scores and grew at a slower pace than the MD-RD group. The RD-only and MD-RD groups did not differ in beginning secondgrade achievement levels or in growth rates.

Summary. In summary, the growth curve analyses for Broad Reading, Letter-Word Identification, and Passage Comprehension yielded similar results. Across all three measures, the NA and MD-only groups started with significantly higher second-grade W scores and grew significantly slower than the MD-RD group; the MD-RD and RD-only groups did not differ in second-grade starting points or in growth rate. IQ was a significant predictor of initial achievement levels for all three reading achievement tests. IQ was a significant predictor of growth rate for Letter-Word Identification but not for Broad Reading or Passage Comprehension.

Table 6

Woodcock-Johnson Reading Letter-Word Identification Subtest Growth Curve Results

\begin{tabular}{|c|c|c|c|}
\hline \multirow[b]{2}{*}{ Effect } & \multicolumn{3}{|c|}{ Maximum likelihood estimate } \\
\hline & Baseline model ${ }^{\mathrm{a}}$ & Model $1^{b}$ & Model $2^{\mathrm{c}}$ \\
\hline Intercept & $455.20 *$ & $440.38 *$ & $441.92 *$ \\
\hline Slope & $8.71 *$ & $9.92 *$ & $9.70 *$ \\
\hline Variance (intercept) ${ }^{\mathrm{d}}$ & $240.33 *$ & $82.53 *$ & $76.22 *$ \\
\hline Variance (slope) & 1.63 & 1.31 & 0.82 \\
\hline$r$ (intercept slope) & -0.43 & 0.11 & -0.04 \\
\hline Intercept on NA & & $26.57 *$ & $23.66^{*}$ \\
\hline Slope on NA & & $-1.51 *$ & $-2.16^{*}$ \\
\hline Intercept on RD only & & 3.05 & 2.14 \\
\hline Slope on RD only & & -0.53 & -0.84 \\
\hline Intercept on MD only & & $26.98 *$ & $25.67 *$ \\
\hline Slope on MD only & & $-2.34 *$ & $-2.54 *$ \\
\hline Intercept on gender & & & -0.51 \\
\hline Slope on gender & & & 0.62 \\
\hline Intercept on ethnicity & & & 1.91 \\
\hline Slope on ethnicity & & & 0.29 \\
\hline Intercept on income & & & -1.83 \\
\hline Slope on income & & & 0.10 \\
\hline Intercept on IQ & & & $0.23 *$ \\
\hline Slope on IQ & & & $0.06^{*}$ \\
\hline
\end{tabular}

Note. $\mathrm{NA}=$ children with normal achievement in mathematics and in reading; RD only = children with difficulties in reading but not in mathematics; MD only = children with difficulties in mathematics but not in reading; MD-RD only = children with difficulties in mathematics as well as in reading.

a Baseline model: no achievement groups and no predictor variables. ${ }^{\mathrm{b}}$ Model 1: achievement groups (MD-RD as reference group) and no predictor variables. ${ }^{\mathrm{c}}$ Model 2: achievement groups and time-invariant predictor variables (gender, ethnicity, Income Year 1, full scale IQ).

${ }^{\mathrm{d}}$ The variance of the corresponding parameter.

$* p<.05$. 


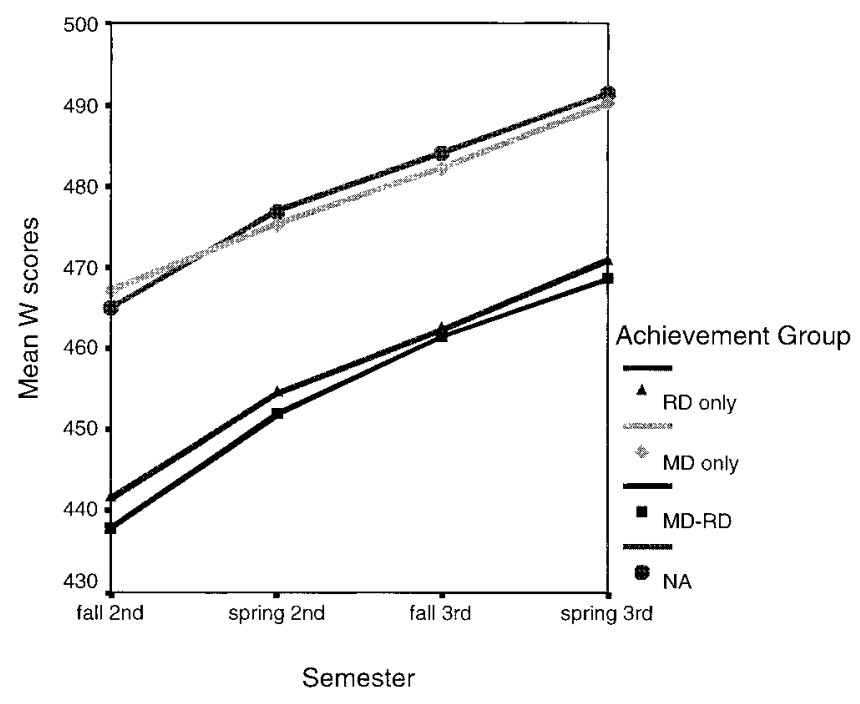

Figure 5. Growth trajectories on the Woodcock-Johnson PsychoEducational Battery-Revised, Form A (WJ), Letter-Word Identification subtest, by achievement group. Points represent the mean Letter-Word Identification scores. W scores $=$ Rasch-scaled scores from the WJ; RD only $=$ difficulties in reading but not in mathematics; MD only $=$ difficulties in mathematics but not in reading; MD-RD = difficulties in mathematics as well as in reading; NA = normal achievement in mathematics and in reading.

\section{Analyses of Instructional Effects}

Finally, we examined several instructional variables that might influence children's growth, namely, whether children received specialized intervention, whether children were retained in second grade, and the nature of the mathematics curriculum children received.

The percentages of children, by achievement group, who received specialized intervention in mathematics and reading in second and third grades are in Table 8. Data are also included for children who may have received specialized intervention in one year but not in another year. Children received reading intervention more often than mathematics intervention, regardless of their achievement group. Reading intervention was even more common than mathematics intervention among children with MD only (i.e., $39 \%$ vs. $13 \%)$.

Concerning retention, none of the children in the NA or MDonly groups were retained in second grade. However, 4 children (10\%) in the MD-RD group and 7 children (16\%) in the RD-only group were held back. The retention decisions seemed to be based more on reading abilities than on mathematics abilities. Although the children's average level of reading and mathematics performance was below that of the nonretained children in their achievement group at all four time points, the growth rates of the retained and nonretained children were about the same, with the exception of the RD-only children who appeared to grow more slowly in mathematics achievement. Within the achievement group, the IQ scores for children who were retained were at about the same level as those for children who were promoted.

Finally, we conducted an analysis of the effects of instructional program (i.e., problem centered vs. traditional) on children's achievement growth in mathematics. Because this variable was not time invariant (i.e., some children received one type of instruction in second grade and the other type in third grade), we analyzed the data separately by grade. We conducted analyses of variance (ANOVAs) with type of instruction and achievement group as between-subjects factors and WJ Broad Mathematics W scores (Time 1 in fall and Time 2 in spring) as a within-subject factor. There were no main effects or interactions involving type of instruction in second grade, but there was a significant Time $\times$ Program interaction in third grade, $\mathrm{F}(3,165)=10.24, p<.002$. The mean WJ Broad Mathematics W scores for second and third graders, by type of instruction and time of testing, are graphically displayed in Figure 7. There was no effect of type of instruction on math scores at Time 1, but there was a significant effect favoring traditional instruction at Time $2(p<.004)$. Children who received traditional instruction made more progress in mathematics achievement in third grade than did children who received problem-centered instruction, regardless of achievement group.

\section{Discussion}

In second grade, we identified four groups of children with different patterns of achievement (i.e., MD only, MD-RD, RD only, and NA). We examined each group's growth in reading and in mathematics longitudinally over a 2-year period. The MD-only

Table 7

Woodcock-Johnson Reading Passage Comprehension Subtest Growth Curve Results

\begin{tabular}{|c|c|c|c|}
\hline \multirow[b]{2}{*}{ Effect } & \multicolumn{3}{|c|}{ Maximum likelihood estimate } \\
\hline & Baseline model $^{\mathrm{a}}$ & Model $1^{\mathrm{b}}$ & Model $2^{\mathrm{c}}$ \\
\hline Intercept & $466.46^{*}$ & $450.73^{*}$ & $454.57 *$ \\
\hline Slope & $7.97 *$ & $10.62 *$ & $10.34 *$ \\
\hline Variance (intercept) ${ }^{\mathrm{d}}$ & $262.31 *$ & $93.39 *$ & $69.86 *$ \\
\hline Variance (slope) & $10.29 *$ & $4.77 *$ & $4.78 *$ \\
\hline$r$ (intercept slope) & $-0.83^{*}$ & $-0.60 *$ & $-0.65 *$ \\
\hline Intercept on NA & & $29.36^{*}$ & $23.28 *$ \\
\hline Slope on NA & & $-4.43 *$ & $-4.24 *$ \\
\hline Intercept on RD only & & 4.17 & 2.47 \\
\hline Slope on RD only & & -0.15 & -0.10 \\
\hline Intercept on MD only & & $26.97 *$ & $24.40 *$ \\
\hline Slope on MD only & & $-5.51 *$ & $-5.34 *$ \\
\hline Intercept on gender & & & -2.29 \\
\hline Slope on gender & & & 0.43 \\
\hline Intercept on ethnicity & & & 2.56 \\
\hline Slope on ethnicity & & & -0.57 \\
\hline Intercept on income & & & -2.60 \\
\hline Slope on income & & & 0.54 \\
\hline Intercept on IQ & & & $0.48 *$ \\
\hline Slope on IQ & & & -0.01 \\
\hline
\end{tabular}

Note. $\mathrm{NA}=$ children with normal achievement in mathematics and in reading; $\mathrm{RD}$ only $=$ children with difficulties in reading but not in mathematics; MD only = children with difficulties in mathematics but not in reading; MD-RD only = children with difficulties in mathematics as well as in reading.

${ }^{a}$ Baseline model: no achievement groups and no predictor variables. ${ }^{\mathrm{b}}$ Model 1: achievement groups (MD-RD as reference group) and no predictor variables. ${ }^{\mathrm{c}}$ Model 2: achievement groups and time-invariant predictor variables (gender, ethnicity, Income Year 1, full scale IQ). $\mathrm{d}$ The variance of the corresponding parameter.

$* p<.05$. 


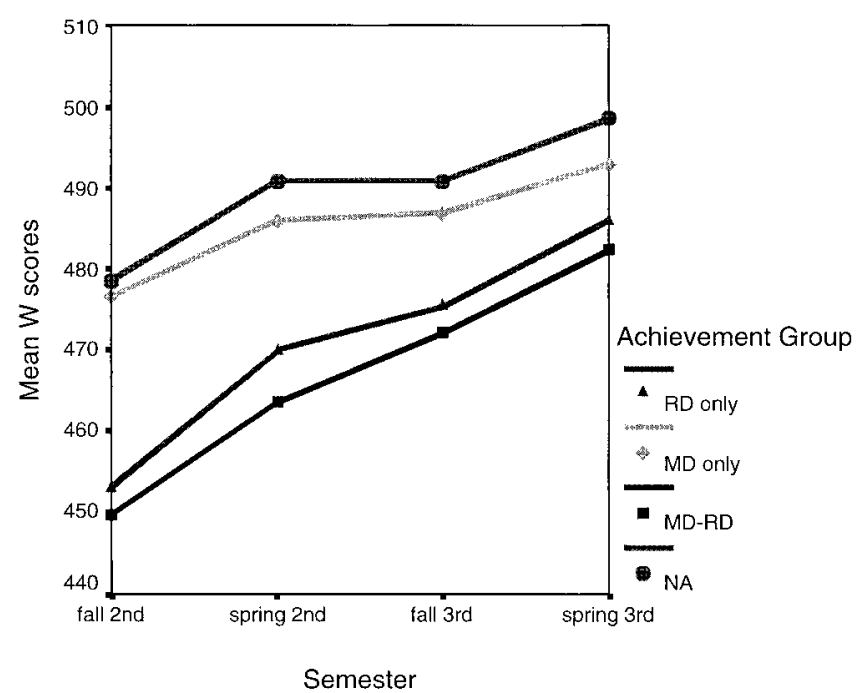

Figure 6. Growth trajectories on the Woodcock-Johnson PsychoEducational Battery-Revised, Form A (WJ), Passage Comprehension subtest, by achievement group. Points represent the mean Passage Comprehension scores. $\mathrm{W}$ scores $=$ Rasch-scaled scores from the WJ; RD only $=$ difficulties in reading but not in mathematics; MD only $=$ difficulties in mathematics but not in reading; MD-RD = difficulties in mathematics as well as in reading; $\mathrm{NA}=$ normal achievement in mathematics and in reading.

group started at about the same mathematics level as the MD-RD group, and the RD-only group started at about the same level as the NA group. Children with MD only grew at a faster rate than children with MD-RD in mathematics (in Broad Mathematics as well as in Calculation and Applied Problems on the WJ), even when we accounted for IQ and income level. Reading abilities influenced children's growth in mathematics; we also observed that children identified with RD only in the beginning of second grade performed at about the same level in mathematics as children with MD only and at a lower level than NA children by the end of third grade. Thus it appears that children who start out with specific reading difficulties are at risk for developing secondary or associated mathematics difficulties as they progress through elementary school.

How do reading abilities influence children's growth in mathematics? The mathematics tasks used in the present study were given orally and did not require reading. However, reading competencies themselves may reflect or even determine growth in vocabulary and language comprehension (Stanovich, 1991). Children who do not read well have less access to language, at least in its written form. Some areas of mathematics, such as word problems and number combinations, may be mediated by language (Hanich et al., 2001; Jordan, Levine, \& Huttenlocher, 1995). For example, verbal counting strategies help children get correct answers on addition and subtraction combinations (Geary, 1994), and an understanding of number words, relational words, and complex syntactic structures facilitates word problem solving (Levine, Jordan, \& Huttenlocher, 1992). Certain arithmetic skills (e.g., fact retrieval) probably are acquired in a language-specific format (e.g., Dehaene, Spelke, Pinel, Stanescu, \& Tsivkin, 1999; Geary, 1993). The findings of the present study complement previous work in which second graders with MD only had a different profile than children with MD-RD on cognitive variables related to mathematics competence. In particular, MD-only children performed better than MD-RD children on mathematics tasks that have a basis in language but not on those that rely on "purer" numerical understanding (e.g., numerical magnitudes). The extent to which children can use verbal compensatory strategies to solve different kinds of mathematics problems remains an open question.

In contrast, mathematics abilities do not seem to have a significant influence on reading growth. Children with RD only grew at the same rate as children with MD-RD in reading, when IQ and income level were held constant. Moreover, reading difficulties identified in second grade seemed to be remarkably stable throughout the test period, regardless of whether they represented specific (RD only) or garden-variety (MD-RD) problems. Our findings are in line with other work (Fletcher et al., 1994). RD children with a significant discrepancy between IQ and reading achievement have a profile that is similar to RD children without such a discrepancy on cognitive variables related to reading ability, especially with respect to phonological awareness. Many children identified with RD early on do not catch up in their reading skills (e.g., Shaywitz et al., 1995).

The finding that children without MD grew more slowly than children with MD is surprising yet interesting. We speculate that although the WJ is normed through adulthood, the growth of children without MD was limited by an "instructional ceiling." That is, higher level mathematics skills may not have been introduced in the second- or third-grade curricula, causing the growth of children with strong mathematics achievement to level off somewhat at the end of each grade. We note that there was a similar effect in reading (i.e., children without RD grew more slowly than children with RD).

Among our predictor variables, gender and ethnicity did not predict growth in mathematics or in reading. However, income level predicted growth in mathematics (WJ Broad Mathematics) but not in reading. Recall that special services were much more likely to be provided in reading than in mathematics for the children in our study sample. Reading intervention may have leveled the playing field for children with RD, regardless of their income status. IQ, on the other hand, was a consistent predictor of growth in mathematics (WJ Broad Mathematics and Calculation)

Table 8

Percentage of Children, by Achievement Group, Receiving Specialized Intervention in Mathematics and Reading

\begin{tabular}{|c|c|c|c|c|c|c|}
\hline \multirow{2}{*}{$\begin{array}{l}\text { Achievement } \\
\text { group }\end{array}$} & \multicolumn{2}{|c|}{ Second grade } & \multicolumn{2}{|c|}{ Third grade } & \multicolumn{2}{|c|}{$\begin{array}{l}\text { Second or } \\
\text { third grade }\end{array}$} \\
\hline & Math & Reading & Math & Reading & Math & Reading \\
\hline MD only & 4 & 30 & 11 & 28 & 13 & 39 \\
\hline MD-RD & 33 & 90 & 33 & 76 & 40 & 95 \\
\hline RD only & 31 & 87 & 11 & 67 & 36 & 93 \\
\hline NA & 4 & 9 & 2 & 21 & 6 & 23 \\
\hline
\end{tabular}

Note. $\mathrm{MD}$ only = children with difficulties in mathematics but not in reading; $\mathrm{MD}-\mathrm{RD}=$ children with difficulties in mathematics as well as in reading; RD only = children with difficulties in reading but not in mathematics; NA = children with normal achievement in mathematics and in reading. 


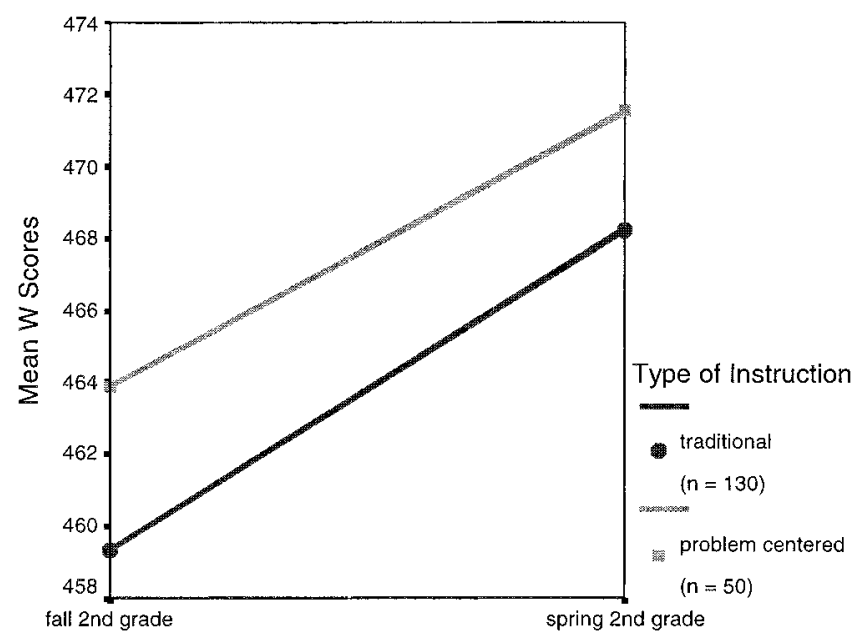

Semester

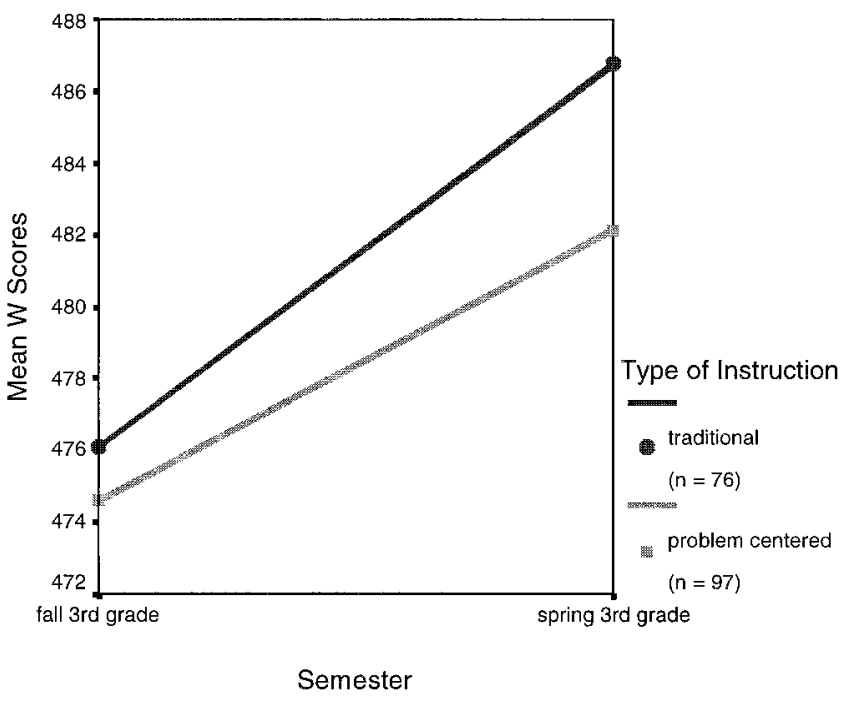

Figure 7. Growth trajectories on the Woodcock-Johnson PsychoEducational Battery-Revised, Form A (WJ), Broad Mathematics composite for second-grade (top panel) and third-grade (bottom panel) students, by type of instructional program. Points represent the mean Broad Mathematics scores. W scores $=$ Rasch-scaled scores from the WJ.

and in reading (WJ Letter-Word Identification), with children with higher IQ scores growing faster than children with lower IQ scores. The effect of IQ may be harder to reduce with specialized intervention than the effect of income.

The use of two distinct mathematics approaches to teaching mathematics (i.e., problem centered vs. traditional) in our sample of schools gave us the opportunity to look at the effects of these approaches on children with MD. However, we could not include the instructional data in our growth models because the approach with which children were taught varied between second and third grades for some children. In supplementary ANOVAs, there was a significant effect of instructional approach in third grade but not in second grade, such that in third grade children taught with a traditional approach made more progress than did children taught with a problem-centered approach. This finding held for all achievement groups: Children with MD did not respond differently to instructional approaches than children without MD. Our finding certainly deserves further attention, as the effects of instructional programs may not be seen until later. Moreover, broad-based achievement tests (such as the one used in the present study) might not adequately assess the mathematics taught in problem-centered approaches. Such tests may also fail to detect more subtle deficits related to mathematical fluency (e.g., the ability to retrieve facts and algorithms automatically).

The amount of verbal explanations or feedback provided by teachers as well as the amount of reading and language required during mathematics instruction also should be observed in subsequent investigations. Such information could help us understand why children with MD only and MD-RD show differential achievement growth patterns in mathematics. For example, mathematics instruction that has a strong basis in reading and language may penalize children with MD-RD as well as children with RD only (who appear to be at risk for growing into mathematics difficulties as well). In contrast, language-based mathematics instruction may be beneficial to children with MD only, allowing them to take advantage of their relative strengths in reading. Such an approach may help children with specific MD to compensate for and grow out of some of their difficulties.

In conclusion, although reading difficulties in children are stable over time, regardless of whether they are accompanied by mathematics difficulties, mathematics difficulties are not. Outcomes for children with specific MD are better than those for children with comorbid MD and RD. In future longitudinal research, we should examine children's growth trajectories in later elementary school as well as the growth patterns of children prior to second grade. The latter analyses may help us identify precursors of mathematics difficulties in children.

\section{References}

Arbuckle, J. L. (1999). AMOS (Version 4.0) [Computer software and manual]. Chicago: Smallwaters.

Blachman, B. A. (1994). What we have learned from longitudinal studies of phonological processing and reading, and some unanswered questions: A response to Torgesen, Wagner, and Rashotte. Journal of Learning Disabilities, 27, 287-291.

Bryk, A. S., \& Raudenbush, S. W. (1987). Application of hierarchical linear models to assessing change. Psychological Bulletin, 101, 147158.

Bryk, A. S., \& Raudenbush, S. W. (1992). Hierarchical linear models: Applications and data analysis methods. Newbury Park, CA: Sage.

Byrne, B., Freebody, P., \& Gates, A. (1992). Longitudinal data on the relations of word-reading strategies to comprehension, reading time, and phonemic awareness. Reading Research Quarterly, 27, 141-151.

Dehaene, S., Spelke, E., Pinel, P., Stanescu, R., \& Tsivkin, S. (1999, May). Sources of mathematical thinking: Behavioral and brain-imaging evidence. Science, 284, 970-974.

Fletcher, J. M., Shaywitz, S. E., Shankweiler, D. P., Katz, L., Liberman, I. Y., Fowler, A., et al. (1994). Cognitive profiles of reading disability: Comparisons of discrepancy and low achievement definitions. Journal of Educational Psychology, 85, 1-18.

Foorman, B. R., Francis, D. J., Winikates, D., Mehta, P., Schatschneider, C., \& Fletcher, J. M. (1997). Early interventions for children with reading disabilities. Scientific Studies in Reading, 1, 255-276.

Francis, D. J., Shaywitz, S. E., Stuebing, K. K., Shaywitz, B. A., \& Fletcher, J. M. (1994). The measurement of change: Assessing behavior 
over time and within a developmental context. In G. R. Lyon (Ed.), Frames of reference: Measurement of learning disabilities (pp. 29-58). Baltimore: Brooks.

Francis, D. J., Shaywitz, S. E., Stuebing, K. K., Shaywitz, B. A., \& Fletcher, J. M. (1996). Developmental lag versus deficit models of reading disability: A longitudinal, individual growth curves analysis. Journal of Educational Psychology, 88, 3-17.

Geary, D. C. (1990). A componential analysis of an early learning deficit in mathematics. Journal of Experimental Child Psychology, 49, 363383.

Geary, D. C. (1993). Mathematical disabilities: Cognitive, neuropsychological, and genetic components. Psychological Bulletin, 114, 345-362.

Geary, D. C. (1994). Children's mathematical development: Research and practical applications. Washington, DC: American Psychological Association.

Geary, D. C., Brown, S. C., \& Samaranayake, V. A. (1991). Cognitive addition: A short longitudinal study of strategy choice and speed of processing differences in normal and mathematically disabled children. Developmental Psychology, 27, 787-797.

Geary, D. C., Hamson, C. O., \& Hoard, M. K. (2000). Numerical and arithmetical cognition: A longitudinal study of process and concept deficits in children with learning disability. Journal of Experimental Child Psychology, 77, 236-263.

Geary, D. C., Hoard, M. K., \& Hamson, C. O. (1999). Numerical and arithmetical cognition: Patterns of functions and deficits in children at risk for a mathematical disability. Journal of Experimental Child Psychology, 74, 213-239.

Hanich, L. B., Jordan, N. C., Kaplan, D., \& Dick, J. (2001). Performance across different areas of mathematical cognition in children with learning difficulties. Journal of Educational Psychology, 93, 615-626.

Investigations in number, data, and space. (1998). Menlo Park, CA: Scott Foresman-Addison Wesley.

Jordan, N. C., \& Hanich, L. B. (2000). Mathematical thinking in secondgrade children with different types of learning difficulties. Journal of Learning Disabilities, 33, 567-578.

Jordan, N. C., Hanich, L. B., \& Uberti, H. (in press). Mathematical thinking and learning disabilities. In A. J. Baroody \& A. Dowker (Eds.), The development of arithmetic concepts and skills: The construction of adaptive expertise. Mahwah, $\mathrm{NJ}$ : Erlbaum.

Jordan, N. C., Levine, S. C., \& Huttenlocher, J. (1995). Calculation abilities in young children with different patterns of cognitive functioning. Journal of Learning Disabilities, 28, 53-64.

Jordan, N. C., \& Montani, T. O. (1997). Cognitive arithmetic and problem solving: A comparison of children with specific and general mathematics difficulties. Journal of Learning Disabilities, 30, 624-634.

Levine, S. C., Jordan, N. C., \& Huttenlocher, J. (1992). Development of calculation abilities in young children. Journal of Experimental Child Psychology, 53, 72-103.
Math. (1998). Menlo Park, CA: Scott Foresman-Addison Wesley.

Math trailblazers. (1998). Dubuque, IA: Kendall/Hunt.

Muthén, B. (1991). Analysis of longitudinal data using latent variable models with varying parameters. In L. Collins \& J. Horn (Eds.), Best methods for the analysis of change: Recent advances, unanswered questions, future directions (pp. 1-17). Washington, DC: American Psychological Association.

Ostad, S. A. (1997). Developmental differences in addition strategies: A comparison of mathematically disabled and mathematically normal children. British Journal of Educational Psychology, 67, 345-357.

Rogosa, D. R., Brandt, D., \& Zimowski, M. (1982). A growth curve approach to the measurement of change. Psychological Bulletin, 90, 726-748.

Russell, R. L., \& Ginsburg, H. P. (1984). Cognitive analysis of children's mathematics difficulties. Cognition and Instruction, 1, 217-244.

Shaywitz, B. A., Holford, T. R., Holahan, J. M., Fletcher, J. M., Stuebing, K. K., Francis, D. J., \& Shaywitz, S. E. (1995). A Matthew effect for IQ but not for reading: Results from a longitudinal study. Reading Research Quarterly, 30, 894-906.

Shaywitz, S. E., Escobar, M. D., Shaywitz, B. A., Fletcher, J. M., \& Makuch, R. (1992). Evidence that dyslexia may represent the lower tail of a normal distribution of reading ability. The New England Journal of Medicine, 326, 145-150.

Shaywitz, S. E., Shaywitz, B. A., Fletcher, J. M., \& Escobar, M. D. (1990). Prevalence of reading disability in boys and girls: Results of the Connecticut longitudinal study. Journal of the American Medical Association, 264, 998-1002.

Silver, C. H., Pennett, H. D., Black, J. L., Fair, G. W., \& Balise, R. R. (1999). Stability of arithmetic disability subtypes. Journal of Learning Disabilities, 32, 108-119.

Stanovich, K. E. (1991). Discrepancy definitions of reading disability: Has intelligence led us astray? Reading Research Quarterly, 26, 7-29.

Wechsler, D. (1999). Wechsler Abbreviated Scale of Intelligence. San Antonio, TX: Psychological Corporation.

Willett, J. B. (1988). Questions and answers in the measurement of change. In E. Rothkepf (Ed.), Review of research in education (pp. 345-422). Washington, DC: American Educational Research Association.

Willett, J. B., \& Sayer, A. G. (1994). Using covariance structure analysis to detect correlates and predictors of individual change over time. Psychological Bulletin, 116, 363-381.

Woodcock, R. W., \& Johnson, M. B. (1990). Woodcock-Johnson PsychoEducational Battery—Revised. Allen, TX: DLM Teaching Resources.

Received September 21, 2001

Revision received November 14, 2001

Accepted November 15, 2001 